\title{
Electromagnetic and mechanical analyses of the ITER Electron Cyclotron Upper Launcher steering M4 mirrors for the vertical displacement event
}

\author{
Avelino Mas Sánchez ${ }^{\mathrm{a}^{*}}$, René Chavan ${ }^{\mathrm{a}}$, Timothy Goodman ${ }^{\mathrm{a}}$, Phillip Santos Silva ${ }^{\mathrm{a}}$, Matteo Vagnoni ${ }^{\mathrm{a}}$ \\ ${ }^{a}$ Ecole Polytechnique Fédérale de Lausanne (EPFL), Swiss Plasma Center (SPC), CH-1015 Lausanne, Switzerland
}

The mm-wave power exiting the eight In-Vessel waveguides inside the ITER Electron Cyclotron Upper Launcher is reflected by three fixed mirror sets and finally aimed by two independent steering mirrors to specific plasma locations. A design solution for both Upper and Lower Steering M4 Mirrors capable to withstand the loads taking place during normal operation was already proposed. This design is now assessed against the Vertical Displacement Event Category III (VDEIII) linear decay $(36 \mathrm{~ms})$ scenario, which was identified as one of the most stringent load combinations for the steering M4 mirrors.

This paper reports the analyses performed to quantify the mechanical loads induced in the steering M4 mirrors during the VDEIII scenario as well as the structural integrity assessment to validate the design against these loads. The transient electromagnetic simulations show that the highest forces are induced in the reflecting surfaces, which produce a bending moment that tends to rotate upwards the mirrors. The comparison between the categorized stresses obtained from the transient mechanical analyses and the allowable design limits according to the ASME code shows that the design of the steering M4 mirrors is widely capable of withstanding the expected loads taking place during the VDEIII scenario.

Keywords: ITER, EC, Upper Launcher, Steering Mirrors, Electromagnetic analysis, Mechanical analysis

\section{Introduction}

The ITER Electron Cyclotron (EC) system consists of 24 gyrotrons with a total installed power of $24 \mathrm{MW}$ at $170 \mathrm{GHz}$ and $3600 \mathrm{~s}$ pulse length with transmission lines connecting the gyrotrons with an Equatorial Launcher (EL) and four Upper Launchers (UL, Fig. 1). The main functions of the EC system are plasma initiation, central heating, current drive, current profile tailoring, and magneto-hydrodynamic control (in particular, sawteeth and Neo-classical Tearing Mode) in the flat-top phase of the plasma [1].

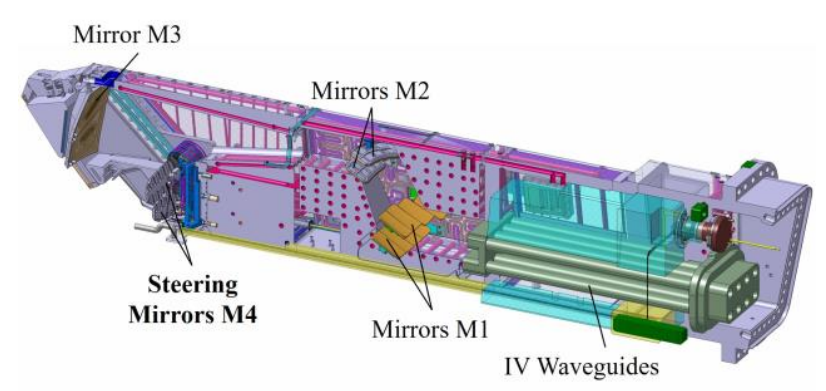

Fig. 1. ITER Electron Cyclotron Upper Launcher

The UL quasi-optical system [2] includes eight beams launched from two rows of four In-Vessel (IV) waveguides [3]. This mm-wave power is reflected by sets of two mirrors (upper and lower, four beams each); initially on the focusing M1 mirror set [4], subsequently on the flat M2 mirror set [5], then refocusing on the M3 mirror (upper and lower mirrors are grouped in one entity) [6] and finally aimed by the steering M4 mirror set [7] to specific plasma locations.

An optimized design (Fig. 2) of both Upper Steering Mirror (USM) and Lower Steering Mirror (LSM) capable to withstand the loads taking place during normal operation was already described in [7].

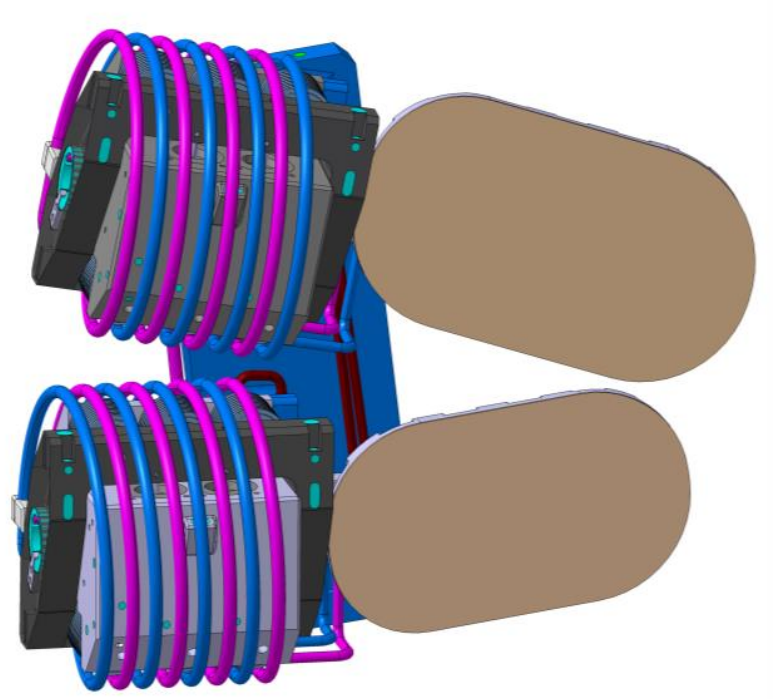

Fig. 2. Steering M4 mirror assembly (USM of the top, LSM of the bottom)

The Vertical Displacement Event Category III (VDEIII) linear decay (36 ms) scenario was identified as one of the most stringent load combinations for the steering M4 mirrors. This event is initiated by a loss of vertical plasma control. Then, the plasma drifts vertically while first maintaining its current. A thermal quench finally occurs during the vertical drift followed by a subsequent current quench [8].

This paper reports the analyses performed to quantify the mechanical loads induced in the steering M4 mirrors during the VDEIII as well as the structural integrity assessment to validate the design against these loads. These analyses only cover the steering mirrors and rotor (the rest of components such as stator, bellows or springs are analyzed by other studies [9]). 


\section{Electromagnetic analyses}

Two separate transient electromagnetic simulations are carried out with ANSYS Workbench 19.2 Maxwell [10] in order to evaluate the electromagnetic forces induced in the USM and the LSM during the VDEIII scenario. In this approach, the steering mirrors are accurately modelled in independent simulations in which the time-dependent magnetic fields obtained from the VDEIII analysis of the overall UL [11] are applied as inputs.

The geometry used for the overall electromagnetic analysis of the UL consisted of a 20-degree tokamak sector, which included the vacuum vessel, blanket modules, equatorial and upper ports, central solenoid, poloidal and toroidal field coils. Due to the size of this numerical model, the internal UL subcomponents (such as the steering M4 mirrors) cannot be detailed enough to provide reliable values of the induced forces in these components. Therefore, this sub-modelling analysis strategy is developed in order to accurately obtain the volumetric forces in the different steering mirror components.

\subsection{Model description}

\subsubsection{Geometrical model and mesh}

The geometrical models used for these analyses cover the reflecting surface, mirror structure and rotor. The thickness of the mirror connection arm was enlarged in relation to the geometry described in [7] (from $10 \mathrm{~mm}$ to $20 \mathrm{~mm}$ ) in order to improve its mechanical resistance (justified in section 3). Simplified flexure pivots are also included since they will be also considered in the conjugated mechanical analysis. Bolts, washers and alignment pins are removed from the model since they are not significant for the electromagnetic performance of the assembly.

In addition, three couples of Helmholtz coils (one for each magnetic field component) are included in the model (Fig. 3). These coils are aimed to produce a magnetic field (representative of the VDEIII scenario) by applying in them the suitable time-dependent current. To avoid the geometrical clash among them, a different radius is used for each couple of Helmholtz coils. Radiuses of $1000 \mathrm{~mm}, 1100 \mathrm{~mm}$ and $1200 \mathrm{~mm}$ are used for the Helmholtz coils perpendicular to the axis X, Y and $Z$, respectively. Two concentric spheres of $1.5 \mathrm{~m}$ and $8 \mathrm{~m}$ radius are also defined to model the vacuum volume where the magnetic fields are developed. These two domains are stablished to independently optimize the mesh size.

Element size values of $10 \mathrm{~mm}, 100 \mathrm{~mm}$ (only on the surface), $300 \mathrm{~mm}$ and $3000 \mathrm{~mm}$ are applied to the USM and LSM components, Helmholtz coils, smaller vacuum sphere and larger vacuum sphere, respectively. The overall number of elements defined in the numerical models are 588007 and 562818 for the USM and LSM simulations, respectively

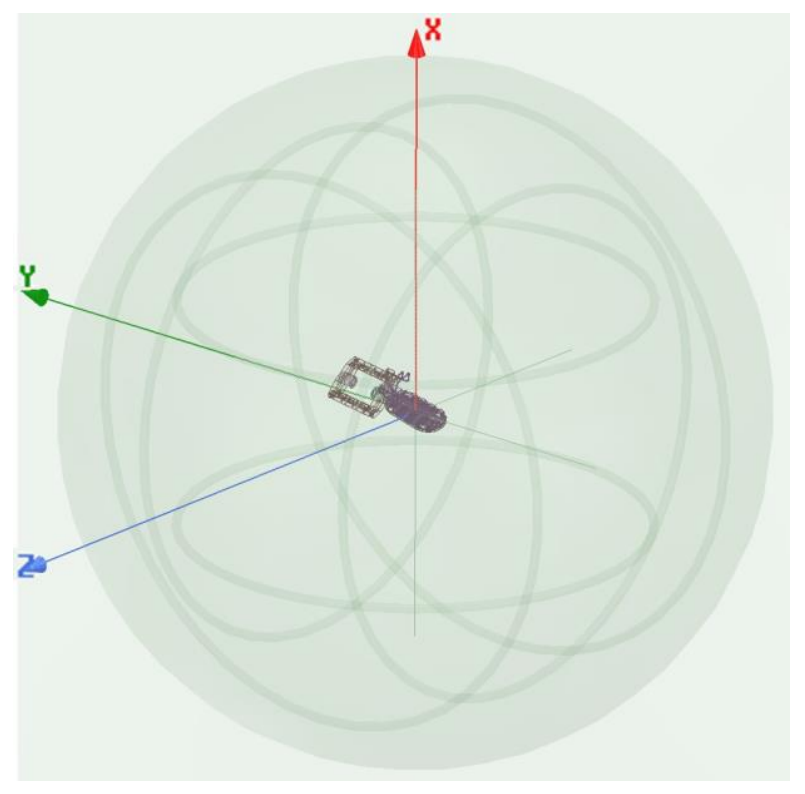

Fig. 3. Helmholtz coils used in the electromagnetic analyses (the local coordinate system is located at the center of the reflecting surfaces and oriented as the global coordinate system)

\subsubsection{Material properties}

The electrical conductivity values [12] related to $\mathrm{CuCrZr}$ alloy (46000000 siemens $/ \mathrm{m}), \quad 316 \mathrm{~L}(\mathrm{~N})-\mathrm{IG}$ (1330000 siemens $/ \mathrm{m})$, Steel Grade $660 \quad(1100000$ siemens $/ \mathrm{m})$ and Ti-6Al-4V (580000 siemens $/ \mathrm{m})$ are applied to the reflecting surface, mirror structure, rotor and flexure pivots, respectively. The relative permeability is set equal to 1 for all the materials.

\subsubsection{Excitations}

The Helmholtz coils are the simplest configuration to generate a known and nearly uniform magnetic field. The Helmholtz coils consist in two identical circular coils located on the same axis and separated by a distance equal to the coils' radius. If each coil carries an equal electric current in the same direction, the magnetic field at the center of the Helmholtz can be calculated with following expression:

$$
\left.\vec{B}\right|_{z=0}=\frac{\mu_{0} I}{\left(\frac{5}{4}\right)^{3 / 2} a}
$$

Where $\left.\vec{B}\right|_{z=0}$ is the magnetic field at the center of the Helmholtz coils, $\mathrm{I}$ is the current passing through each coil (in a single turn), $a$ is the coils radius (as well as the distance between them) and $\mu_{0}=4 \pi \times 10^{-7} \mathrm{H} \cdot \mathrm{m}^{-1}$ is the permeability of the free space.

The electromagnetic analysis of the overall EC UL was initially performed for the VDEIII scenario [11]. The time history of the magnetic field $\left(\mathrm{B}_{\mathrm{x}}, \mathrm{B}_{\mathrm{y}}\right.$ and $\left.\mathrm{B}_{\mathrm{z}}\right)$ is then independently averaged in the USM and LSM domains (Fig. 4). The equivalent current is calculated using equation (1) and applied to the terminals defined in the coils. 


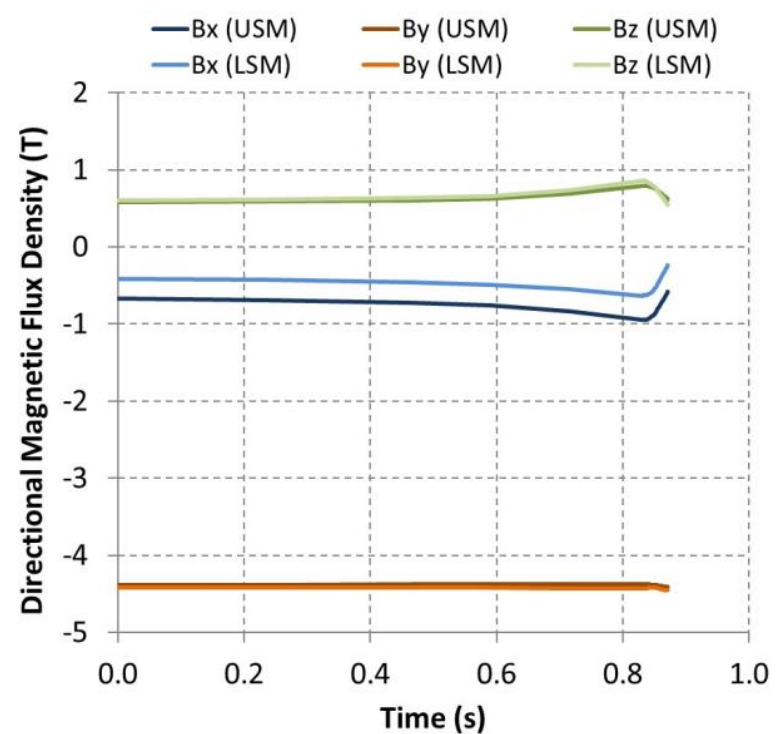

Fig. 4. Time history of the magnetic field in the USM and LSM (VDEIII linear decay $36 \mathrm{~ms}$ )

Fig. 5 shows the evolution of the $\Delta \mathrm{B} / \Delta \mathrm{T}$ for both USM and LSM. The VDEIII scenario starts at $t=0 \mathrm{~s}$. Before $\mathrm{t}=0.83 \mathrm{~s}$ the plasma is drifting but the magnetic field is almost constant until $t=0.83 \mathrm{~s}$, time when the thermal quench occurs. After this instant the current drops (and therefore the magnetic field) for $36 \mathrm{~ms}$.

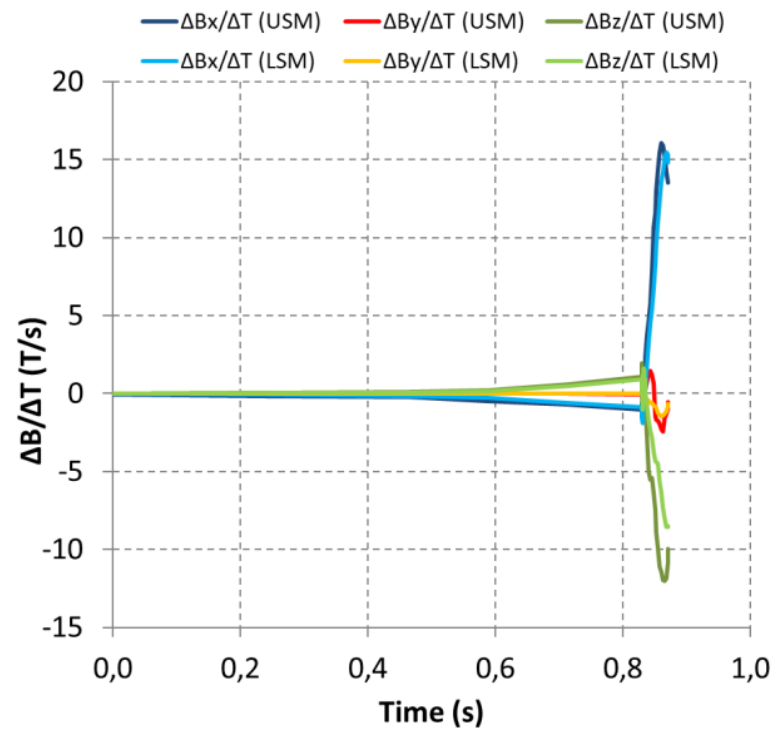

Fig. 5. $\Delta \mathrm{B} / \Delta \mathrm{T}$ time history for the USM and LSM

\subsection{Results}

\subsubsection{Magnetic field}

Fig. 6 and Fig 7 show the magnetic field at $\mathrm{t}=$ $0.8702 \mathrm{~s}$ for the USM and at $\mathrm{t}=0.8677 \mathrm{~s}$ for the LSM, respectively (these points correspond to the times when the highest mechanical stresses are developed, see section 3). It can be seen in these pictures that the magnetic field is very uniform in the vicinity of both USM and LSM. The comparison between the target and the generated magnetic field evolution at the origin of coordinates (local coordinate system) shows a maximum error of $0.2 \%$.

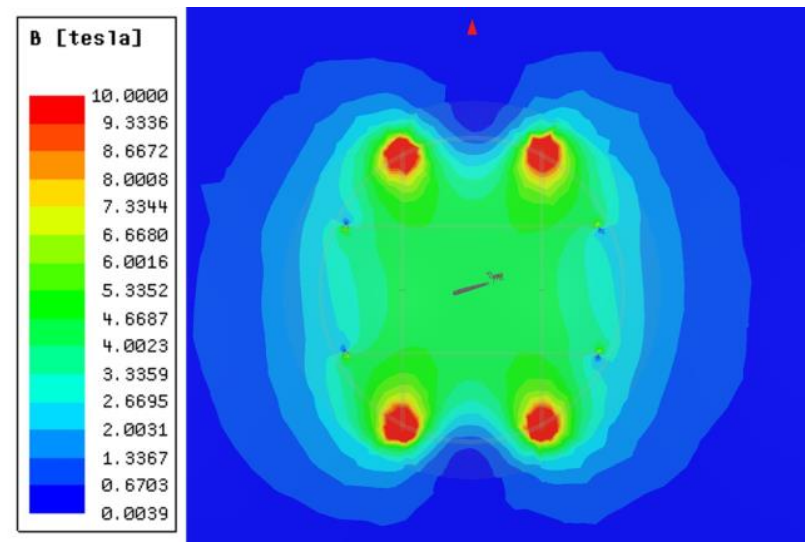

Fig. 6. Magnetic field (modulus) on the plane XY calculated in the USM simulation at $\mathrm{t}=0.8702 \mathrm{~s}$

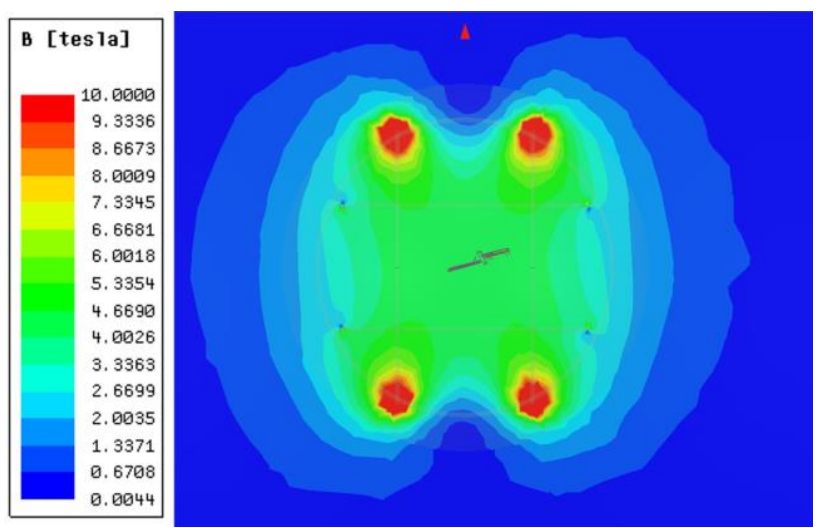

Fig. 7. Magnetic field (modulus) on the plane XY calculated in the LSM simulation at $\mathrm{t}=0.8677 \mathrm{~s}$

\subsubsection{Current density}

The two largest magnetic field variations $(\Delta B / \Delta T)$ are along the radial and vertical axes ( $\mathrm{X}$ axis and $\mathrm{Z}$ axis, Fig. 5). These magnetic field fluctuations induce a current density in the conductive materials (Fig. 8 and Fig. 9), specially the radial one since this magnetic field component is almost perpendicular to the Steering Mirrors.

Most of the current density is developed in the reflecting surfaces (factor 10 compared with the current density developed in mirror structure or rotor) because of the much higher electrical conductivity of the $\mathrm{CuCrZr}$ [12]. This highlights the importance of limiting the reflecting surface thickness at the expense of reducing the mirror heat dissipation capability during the normal mm-wave operation [7]. The maximum current density values induced in the USM and LSM are $4.82 \cdot 10^{7} \mathrm{~A} / \mathrm{m}^{2}$ and $4.26 \cdot 10^{7} \mathrm{~A} / \mathrm{m}^{2}$, respectively. This $10 \%$ difference can be explained due to the larger dimensions of the USM reflecting surface. 


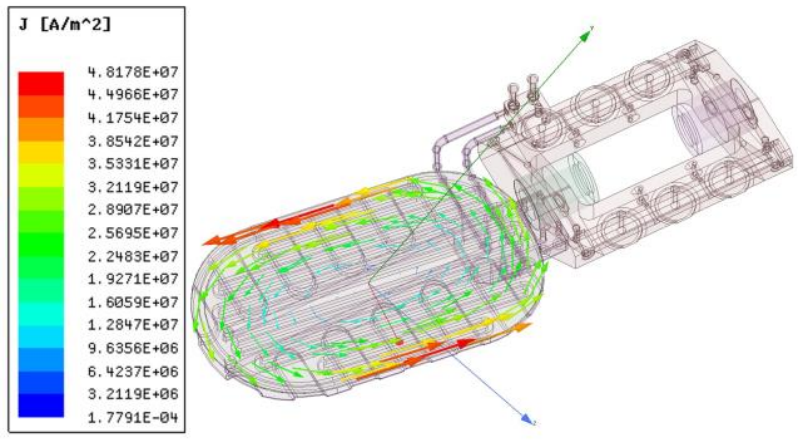

Fig. 8. Current density in the USM at $\mathrm{t}=0.8702 \mathrm{~s}$

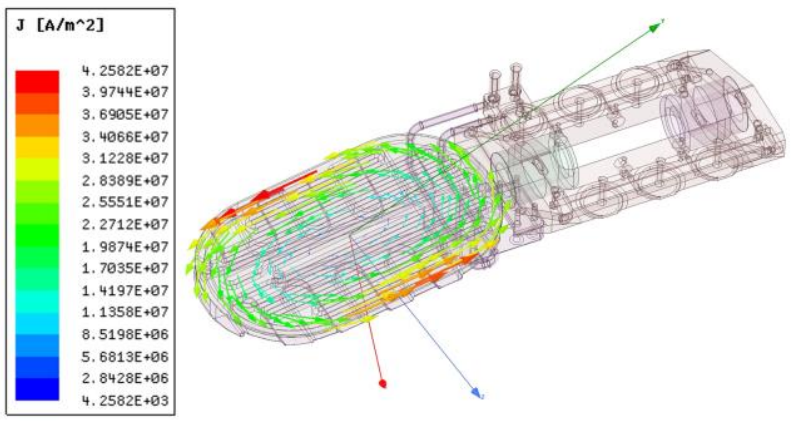

Fig. 9. Current density in the LSM at $\mathrm{t}=0.8677 \mathrm{~s}$

\subsubsection{Induced forces}

In line with what mentioned in the previous section, the highest volumetric forces take place in the reflecting surfaces (also factor 10). The largest contribution to these forces is mainly produced due to the toroidal field (Y axis, Fig. 4), which is the largest magnetic field component. The volumetric forces (Fig. 10 and Fig. 11) create a bending moment that tends to rotate the mirror mainly around the $\mathrm{Z}$ axis (local coordinate system).

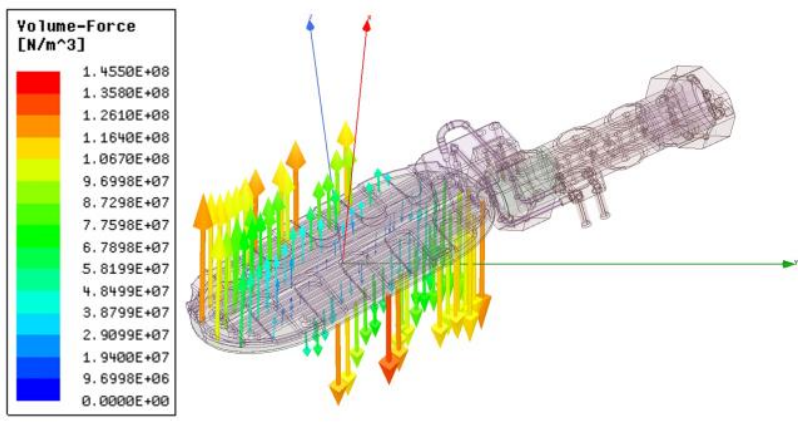

Fig. 10. Volumetric forces induced in the USM at $\mathrm{t}=0.8702 \mathrm{~s}$

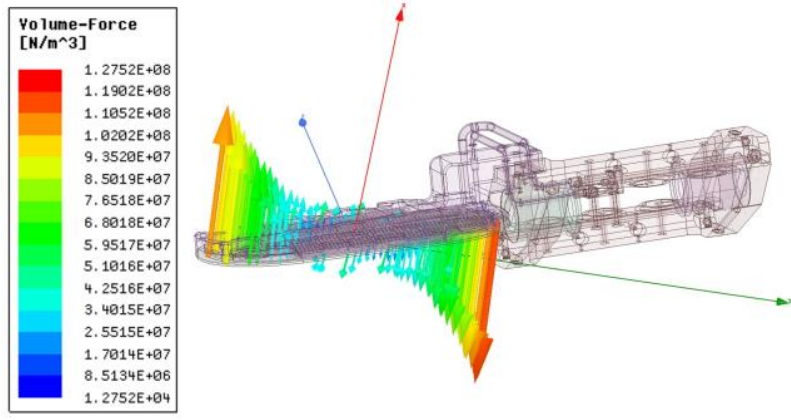

Fig. 11. Volumetric forces induced in the LSM at $\mathrm{t}=0.8677 \mathrm{~s}$
The induced forces are also larger for the USM (maximum value of $1.45 \cdot 10^{8} \mathrm{~N} / \mathrm{m}^{3}$ ) compared with ones in the LSM (maximum value of $1.27 \cdot 10^{8} \mathrm{~N} / \mathrm{m}^{3}$ ). This is also justified based on the larger dimensions of the USM.

The time evolution of the torque induced in both USM and LSM regarding the local coordinate system is plotted in Fig. 12. Before $\mathrm{t}=0.83 \mathrm{~s}$ the plasma current is almost constant so the induced torque is basically 0 . Then, the thermal quench occurs producing a linear current drop for $36 \mathrm{~ms}$. At this moment, the induced torque starts increasing, reaching peak values of -95.0 $\mathrm{Nm}, 92.8 \mathrm{Nm}$ and $584.3 \mathrm{Nm}$ according to the radial, toroidal and vertical axes, respectively for USM and $64.4 \mathrm{Nm}, 63.5 \mathrm{Nm}$ and $406 \mathrm{Nm}$ around the radial, toroidal and vertical axes, respectively for the LSM.

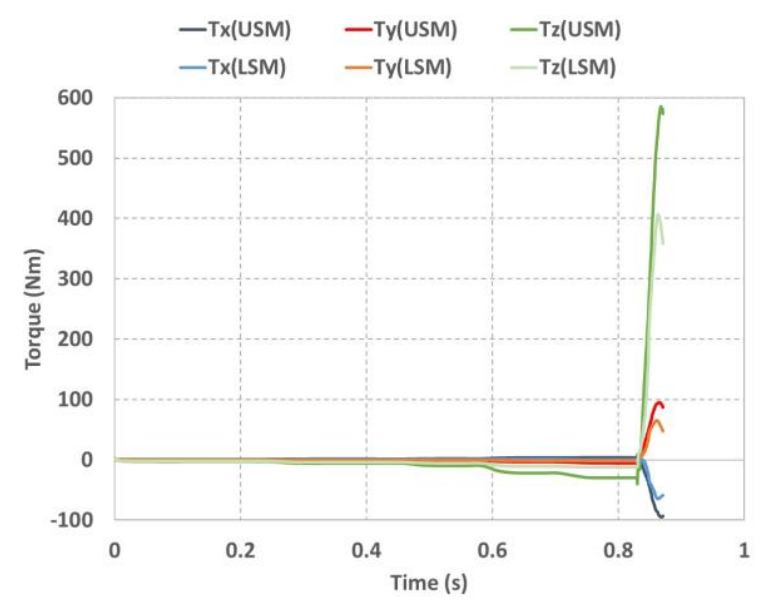

Fig. 12. Time history of the overall induced torque

\section{Mechanical analyses}

Two transient mechanical analyses, based on the calculated volumetric forces, are performed in ANSYS Workbench 19.2 Transient Structural [10] in order to assess the mechanical integrity in terms of plastic collapse of the USM and LSM against the loads taking place during the VDEIII scenario. These numerical analyses provide the stress distribution produced during the VDEIII event, which will be post-processed and subsequently compared with the allowable design limits available in the fabrication codes.

\subsection{Model description}

\subsubsection{Geometrical model and mesh}

The geometrical models used for USM and LSM mechanical simulations (Fig. 13) cover the reflecting surface, mirror structure and rotor. The mirror connection arm is thickened from $10 \mathrm{~mm}$ [7] to $20 \mathrm{~mm}$ so that the cross-section can withstand the large bending moment induced during the VDEIII event. Simplified flexure pivots are also included to properly define the model boundary conditions. This approach allows us to obtain meaningful results in the rotor, which otherwise would be distorted by applying the boundary conditions on the rotor surfaces themselves. Bolts and washers are 
included in the simulation in order to simulate the bolting process.

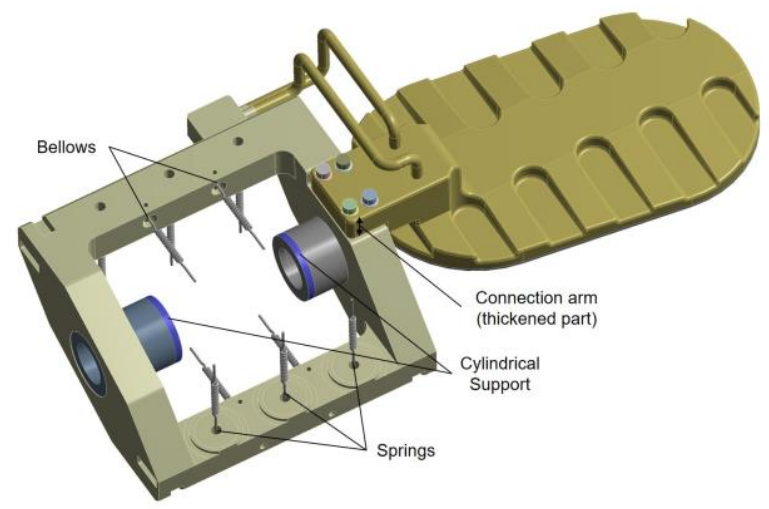

Fig. 13. Geometrical model of the USM thermo-mechanical analysis (the same approach is followed for the LSM)

A uniform element size value of $1.5 \mathrm{~mm}$ is applied to the reflecting surface. A value of $2.5 \mathrm{~mm}$ is considered for the rest of components (mirror structure, rotor, flexure pivots and bolting). The overall number of elements defined in the numerical models are 1400687 and 1190673 for the USM and LSM simulations, respectively.

\subsubsection{Material properties}

The material properties [12] related to $\mathrm{CuCrZr}$ alloy, 316L(N)-IG, Steel Grade 660 and Ti-6Al-4V are applied to the reflecting surface, mirror structure, rotor (and bolting) and flexure pivots, respectively. These properties (density, Young's modulus and Poisson's ratio) are evaluated for the maximum temperature obtained during normal operation [7]. The material behavior for all the materials is considered as linear.

\subsubsection{Contacts and supports}

Frictional contacts are defined between the mirror structure and the washers and between the rotor and the mirror structure (friction coefficient $=0.2$ ) whereas bonded contacts are stablished between the mirror structure pipes and the rotor. The rotor is attached to the space through "spring elements". These elements simulate the springs and bellows behavior providing an additional countervailing force (compression or extension) when the rotor modifies its position. Two cylindrical supports are also added on the flexure pivots in order to simulate the relative tangential movement between rotor and stator.

\subsubsection{Boundary conditions and loads}

The loads considered in these simulations are the ones relative to the VDEIII scenario [8]. These loads can be divided in bolt pre-tension, external forces and moments due to the actuator, springs, cooling coils and flexure pivots reactions, dead weight, cooling pressure and induced electromagnetic loads. These simulations are divided in 38 different time steps for the load application (Table 1). The first 4 time steps correspond to the loads existing in the USM and LSM before the VDEIII transient event occurs (these loads are divided in different time steps to improve the convergence of the numerical problem). The time integration is disabled for these time steps since the inertia effects want to be ignored (these loads are considered as steady state). Then, other 34 time steps are applied to simulate the VDEIII transient event (time integration is on). Each time step is dedicated to solve each volumetric force state exported from the electromagnetic simulation (section 2.2.3).

Table 1. Load steps

\begin{tabular}{cccccccccc}
\hline $\begin{array}{c}\text { Time } \\
\text { step }\end{array}$ & $\begin{array}{c}\text { Time } \\
\text { range }(\mathrm{s})\end{array}$ & $\begin{array}{c}\text { Bolt pre- } \\
\text { tension }(\mathrm{N}) \\
\mathrm{x} 4\end{array}$ & $\begin{array}{c}\text { Spring } \\
\text { reaction } \\
(\mathrm{N}) \times 6\end{array}$ & $\begin{array}{c}\text { Actuator } \\
\text { reaction } \\
(\mathrm{N}) \times \mathrm{x}\end{array}$ & $\begin{array}{c}\text { Coil } \\
\text { reaction } \\
(\mathrm{N}) \times 2\end{array}$ & $\begin{array}{c}\text { Flexure Pivot } \\
\text { reaction } \\
(\mathrm{N} / \mathrm{m}) \times 2\end{array}$ & $\begin{array}{c}\text { Gravity } \\
(\mathrm{m} / \mathrm{s})\end{array}$ & $\begin{array}{c}\text { Cooling } \\
\text { pressure } \\
(\mathrm{MPa})\end{array}$ & $\begin{array}{c}\text { Induced } \\
\text { volumetric } \\
\text { forces }\left(\mathrm{N} / \mathrm{m}^{3}\right)\end{array}$ \\
\hline 1 & $0-1$ & 8000 & - & - & - & - & - & - & - \\
2 & $1-2$ & Lock & 480 & 1546 & 190 & 3.574 & - & - & - \\
3 & $2-3$ & Lock & 480 & 1546 & 190 & 3.574 & 9.8066 & - & - \\
4 & $3-4$ & Lock & 480 & 1546 & 190 & 3.574 & 9.8066 & 4 & - \\
$5-38$ & $4-4.8709$ & Lock & 480 & 1546 & 190 & 3.574 & 9.8066 & 4 & Fig 9-10 \\
\hline
\end{tabular}

\subsection{Results}

\subsubsection{Von-Misses stresses}

The design-by-analysis rules developed in the ASME code [13] are prescribed for the design validation of the Steering Mirrors. These rules are based on the maximum distortion energy yield criterion. Therefore, the stress results obtained from these simulations shall be assessed in terms of von Mises equivalent stresses in order to be compared with the allowable limits. The highest von Mises stress values are obtained at $\mathrm{t}=0.8702 \mathrm{~s}(\mathrm{t}=$ $4.8702 \mathrm{~s}$ in the simulation) for USM (Fig.14) and at $\mathrm{t}=$ $0.8677 \mathrm{~s} \quad(\mathrm{t}=4.8677 \mathrm{~s}$ in the simulation) for LSM (Fig.15).

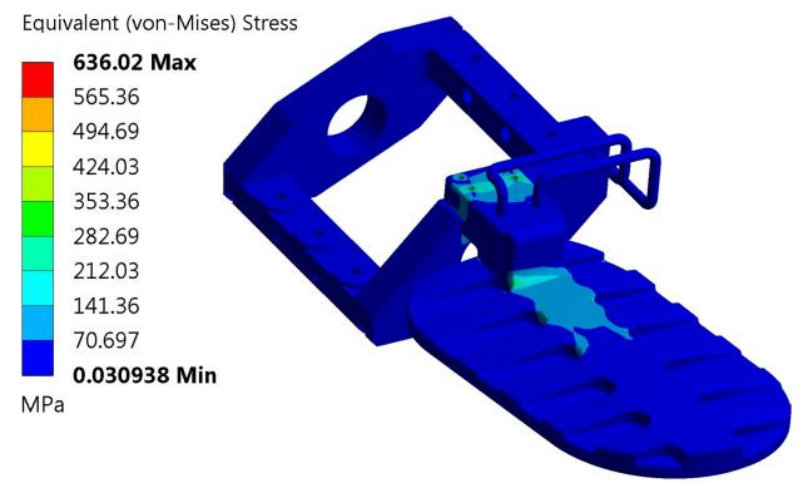

Fig. 14. Von Mises stress field in the USM mirror structure at $\mathrm{t}$ $=4.8702 \mathrm{~s}$ 


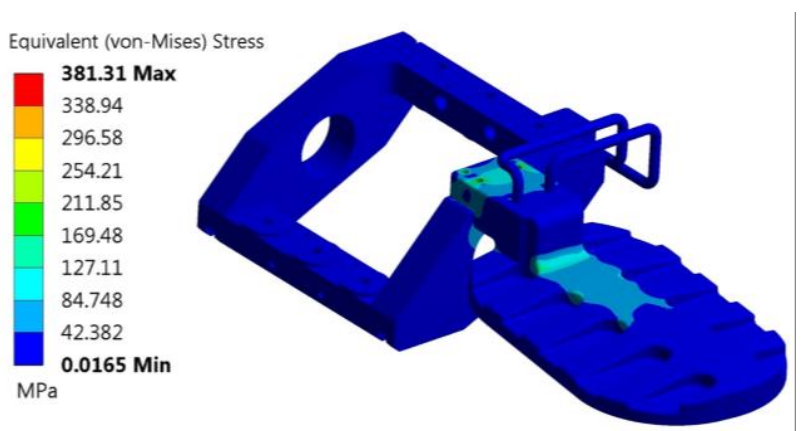

Fig. 15. Von Mises stress field in the LSM mirror structure at $\mathrm{t}$ $=4.8677 \mathrm{~s}$

Comparing both assemblies, the highest stresses are produced in the USM due to its larger dimensions (and therefore, larger induced torque). Although, the stress peak obtained in the Mirror Structure (401 MPa) is lower than in the Rotor $(636 \mathrm{MPa})$, the lower allowable limits of the $316 \mathrm{~L}(\mathrm{~N})-\mathrm{IG}$ (in comparison with those of the Steel Grade 660 [14]) make the USM Mirror Structure the most demanded component in terms of stresses. The stress peak for the Reflecting surface is only 98.6 MPa.

\subsubsection{Structural integrity assessment}

The elastic stress analysis method is considered for the protection assessment against plastic collapse. In this method the stresses are computed using an elastic analysis, classified into categories, and limited to allowable values that have been conservatively established such that a plastic collapse will not occur. The stress categorization is obtained by linearizing the stress (membrane, bending and peak) along the so-called Stress Classification Lines (SCLs). These lines shall be defined through the entire thickness of the considered section and normal to the midline.

The ASME code also considers the evaluation of protection against ratcheting and fatigue, however, this will not be assessed since the VDEIII event is assumed to occurs only once during the machine lifetime [8].

To evaluate protection against plastic collapse the three following limits shall be satisfied:

$$
P_{m} \leq S_{m}
$$

Where $\mathrm{P}_{\mathrm{m}}$ is the general primary membrane equivalent stress and $\mathrm{S}_{\mathrm{m}}$ is the design stress intensity.

$$
P_{L} \leq S_{P L}
$$

Where $P_{L}$ is the local primary membrane equivalent stress (primary membrane equivalent stress when close to discontinuities) and $\mathrm{S}_{\mathrm{PL}}$ is computed as the larger of the quantities shown below:

- $\quad 1.5$ times the design stress intensity $\left(\mathrm{S}_{\mathrm{m}}\right)$

- The yield strength $\left(\mathrm{S}_{\mathrm{y}}\right)$. The previous value shall be used when the ratio of the minimum specified yield strength to the ultimate tensile strength $\left(\mathrm{S}_{\mathrm{u}}\right)$ exceeds 0.70 or the value of $S_{m}$ is governed by timedependent properties

$$
\mathrm{P}_{\mathrm{L}}+\mathrm{P}_{\mathrm{B}} \leq \mathrm{S}_{\mathrm{PL}}
$$

Where $\mathrm{P}_{\mathrm{L}}+\mathrm{P}_{\mathrm{B}}$ is the primary membrane (general or local) plus the primary bending equivalent stress.

Based on the safety classification of the Steering Mirrors as Non-SIC [15] and the categorization of the VDEIII scenario as Category III [8], the damage limit for both assemblies is defined as Emergency [8]. However, the ASME code does not distinguish among different damage limits. For this reason, the SDC-IC code [16] is used to define the implications that the damage limits have in the allowable values. For the service level $\mathrm{C}$ (structural service criteria equivalent to the damage limit emergency), the allowable values for the equations 2), 3) and 4) shall be increased by a factor of 1.2 [17].

The most stressed cross-section of the USM mirror structure takes place at the bolted connection between the mirror and the rotor (Fig. 16). The allowable values for the $316 \mathrm{~L}(\mathrm{~N})-\mathrm{IG}$ at $225^{\circ} \mathrm{C}$ [7] are $125 \mathrm{MPa}$ and 187.5 $\mathrm{MPa}$ for $\mathrm{S}_{\mathrm{m}}$ and $\mathrm{S}_{\mathrm{PL}}$, respectively (which shall be multiplied by 1.2). TABLE 2 reports the verifications performed for each SCL (see Fig. 17). The comparison between the categorized stress and the allowable design limits according to ASME code shows that the Steering Mirror design is widely capable of withstanding the expected loads taking place during the VDEIII scenario (safety margin of 1.18).

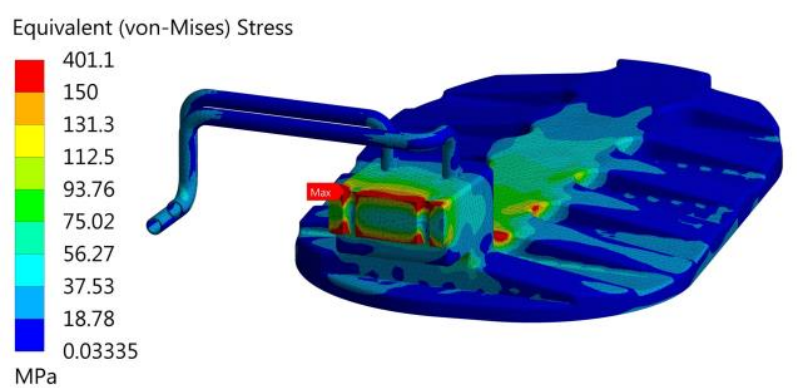

Fig. 16. Selected section in the Mirror Structure for stress verification

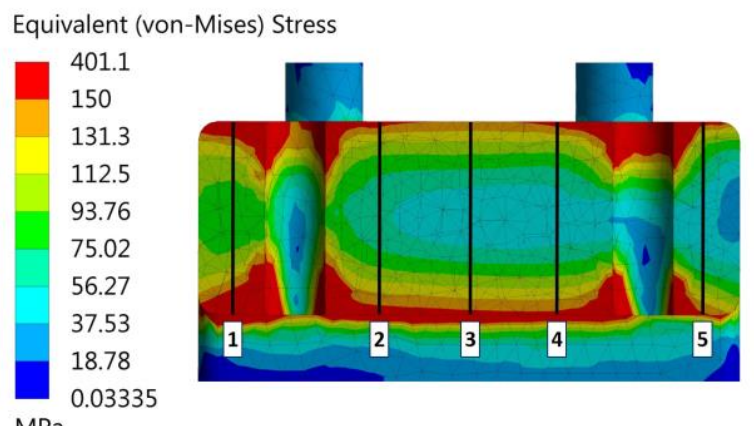

Fig. 17. SCLs for stress verification on the USM Mirror Structure

Table 2. USM Mirror Structure verification (values in MPa)

\begin{tabular}{ccccccc}
\hline SCL & 1 & 2 & 3 & 4 & 5 & Limit \\
\hline $\mathrm{P}_{\mathrm{m}}$ & 60.3 & 35.0 & 28.1 & 35.0 & 32.7 & $1.2 \mathrm{~S}_{\mathrm{m}}=150$ \\
$\mathrm{P}_{\mathrm{L}}$ & - & - & - & - & - & $1.2 \mathrm{~S}_{\mathrm{PL}}=225$ \\
$\mathrm{P}_{\mathrm{L}}+\mathrm{P}_{\mathrm{B}}$ & 189.8 & 155.2 & 152.6 & 155.2 & 136.4 & $1.2 \mathrm{SPL}_{\mathrm{PL}}=225$ \\
\hline
\end{tabular}




\subsubsection{Dynamic amplification factor}

Another two static mechanical simulations of the Steering Mirrors are performed in ANSYS Workbench 19.2 Static Structural [10] in order to determine the relevance of the dynamic effects for the VDEIII scenario. The geometry, mesh, materials, contacts, supports, boundary conditions and loads are identical to the ones described in section 3.1. In this case, the volumetric forces induced in the Steering Mirrors during the VDEIII event are not applied as time-dependent sources. Instead, these loads are introduced as steadystate volumetric forces at $\mathrm{t}=0.8702 \mathrm{~s}$ and $\mathrm{t}=0.8677 \mathrm{~s}$ for the USM and LSM, respectively.

Table 3 and Table 4 summarize the maximum stresses relative to the Reflecting Surface, Mirror Structure and Rotor for both USM and LSM. The maximum values take place at the bolted connection for both mirror structure and rotor and at the central region for the reflecting surface. These tables show that the inertial phenomena are significant since, although the mirrors weight is low, the time scale of only $36 \mathrm{~ms}$ in the VDEIII event makes the inertial contribution relevant. Even though the dynamic approach is recommended, a static simulation including a dynamic amplification factor of 1.22 (highest value of those reported in Table 3 and Table 4) can be used as a first estimation to assess the developed stresses taking place in the steering mirrors or other UL in-vessel mirrors during VDE events through a static approach.

Table 3. Stress comparison for the USM

\begin{tabular}{cccc}
\hline Component & $\begin{array}{c}\text { Dynamic } \\
\text { approach }\end{array}$ & $\begin{array}{c}\text { Static } \\
\text { approach }\end{array}$ & Ratio \\
\hline Reflecting surface & $98.6 \mathrm{MPa}$ & $93.5 \mathrm{MPa}$ & 1.05 \\
Mirror Structure & $401.1 \mathrm{MPa}$ & $361.9 \mathrm{MPa}$ & 1.11 \\
Rotor & $636.0 \mathrm{MPa}$ & $557.6 \mathrm{MPa}$ & 1.14 \\
\hline
\end{tabular}

Table 4. Stress comparison for the LSM

\begin{tabular}{cccc}
\hline Component & $\begin{array}{c}\text { Dynamic } \\
\text { approach }\end{array}$ & $\begin{array}{c}\text { Static } \\
\text { approach }\end{array}$ & Ratio \\
\hline Reflecting surface & $60.9 \mathrm{MPa}$ & $53.2 \mathrm{MPa}$ & 1.14 \\
Mirror Structure & $292.8 \mathrm{MPa}$ & $239.4 \mathrm{MPa}$ & $\mathbf{1 . 2 2}$ \\
Rotor & $381.3 \mathrm{MPa}$ & $341.9 \mathrm{MPa}$ & 1.11 \\
\hline
\end{tabular}

\section{Conclusions}

An analysis strategy was developed in order to evaluate the mechanical integrity of the steering M4 mirrors against the loads occurring during the VDEIII scenario (accidental event).

Two separate transient electromagnetic analyses of the steering M4 mirrors are performed to model the evolution of the electromagnetic fields at the mirrors' surroundings and therefore, obtain the currents and forces induced in the different components. These simulations show that most of the current density is induced in the reflecting surfaces because of the much higher electrical conductivity of the $\mathrm{CuCrZr}$. In line with this, the highest forces also take place in the reflecting surfaces, which create a torque that tends to rotate upwards the mirrors. The higher torque values are obtained in the USM, what can be justified based on its larger dimensions.

Another two transient mechanical analyses are carried out to assess the mechanical integrity in terms of plastic collapse of both USM and LSM against the loads taking place during the VDEIII scenario. For this, the volumetric forces calculated in the electromagnetic simulations are imported and used as an input for the mechanical simulations. These analyses show that the most stressed section corresponds to the bolted connection between the mirror and rotor. The comparison between the categorized stresses and the allowable design limits according to the ASME code increased by a factor of 1.2 (service level C) shows that the design of the reflecting surface, mirror structure and rotor for both USM and LSM is widely capable of withstanding the expected loads taking place during the VDEIII scenario.

Additional analyses shall be performed in order to validate the design of the steering M4 mirrors against the full range of load combinations expected to take place throughout the system life-cycle.

\section{Acknowledgments}

This work was supported in part by the Swiss National Science Foundation. This work was carried out within the framework of the ECHUL consortium, partially supported by the F4E grant F4E-GRT-615. The views and opinions expressed herein do not necessarily reflect those of the European Commission or the ITER Organization.

\section{References}

[1] M. Henderson, The targeted heating and current drive applications for the ITER electron cyclotron system, Physics of Plasmas 22, 021808 (2015)

[2] D. Strauss, Nearing final design of the ITER EC H\&CD Upper Launcher, Fusion Eng. Des. 146, Part A, (2019) 2326.

[3] A. Mas Sánchez, Design status of the double Closure Plate Sub-Plate concept for the ITER Electron Cyclotron Upper Launcher, Fusion Eng. Des. 136 (2018) 503-508.

[4] M. Vagnoni, Structural integrity assessment of an ITER ECH\&CD Upper Launcher mirror (LM1), Fusion Eng. Des. 146, Part A, (2019) 818-821.

[5] P. Santos, Design concept and thermal-structural analysis of a high power reflective mm-wave optical mirror (M2) for the ITER ECH-UL, Fusion Eng. Des. 146, Part A, (2019) 618-621.

[6] M. Vagnoni, Design Concept and Thermal-Mechanical Analysis of the Optical Mirror (M3) for the ITER ECH Upper Launcher, IEEE Transactions on Plasma Science (2020) Early Access.

[7] A. Mas Sánchez, Design and Numerical Analyses of the M4 Steering Mirrors for the ITER Electron Cyclotron Heating Upper Launcher, IEEE Transactions on Plasma Science 47, Issue 12 (2019) 5271-5276.

[8] N. Casal, EC UL Sub-System Load Specification [SSLS52.UL], F4E_D_25QD28 v5.1

[9] P. Santos, Design and Thermal-Structural Analyses of 
Ancillary Components for the Optical Steering-Mirror (M4) for the ITER ECH Upper Launcher, IEEE Transactions on Plasma Science (2020) Early Access.

[10] http://www.ansys.com/

[11] G. Aiello, Magnetic Flux Density on Mirror 4 ARD-051, F4E_D_2DJLT8 v1.0

[12] J. Campbell, ITER Material Properties handbook properties, ITER_D_2239QQ v1.0

[13] ASME Section VIII Division 2 - Alternative rules, 2015

[14] V. Barabash, "Appendix A, Materials Design Limit Data,“ITER_D_222RLN v3.3, March 2013

[15] N. Casal, EC UL System Classification, ITER_D_ 3 CNFEC v3.5

[16] V. Barabash, In-vessel Components, SDC-IC, ITER D ITER D 222RHC, v3.0

[17] G. Sannazzaro, Allowable values and limits in service level $\mathrm{C}$ and $\mathrm{D}$ for ITER mechanical components, ITER_D_3G3SYJ v3.1 